\title{
Spontaneous and Ultraviolet Irradiation-Induced Mutants of Verticillium albo-atrum
}

\author{
By E. W. BUXTON AND A. C. HASTIE* \\ Rothamsted Experimental Station, Harpenden, Hertfordshire
}

(Received 6 November 1961)

\begin{abstract}
SUMMARY
The killing of conidia of Verticillium albo-atrum by ultraviolet irradiation followed first-order kinetics; about $0.5 \%$ of the conidia which survived a $97 \%$ lethal dose were nutritionally deficient mutants. This percentage of mutants among survivors was constant for different wild-type isolates for the first-, second- and third-order irradiations. This regularity implies that most conidia exposed at the first irradiations contained a single haploid nucleus. Adenine-requiring mutants formed pionnotes when grown on an agar medium containing low concentrations of adenine, and the extent of pionnotal formation depended on the position at which adenine synthesis had been blocked by the irradiation. 4-Aminoimidazole5-carboxamide apparently did not act as an extracellular intermediary in adenine synthesis. An acriflavine-resistant mutant arose spontaneously in one of the mutants selected for nutritional deficiency, but mutants resistant to certain other growth inhibitors were not found.
\end{abstract}

\section{INTRODUCTION}

Variation in the soil-borne plant pathogenic fungus Verticillium albo-atrum has been recorded by Isaac (1949), Waggoner (1956), Robinson, Larson \& Walker (1957) and Van den Ende (1958). Each confirmed the occurrence of the colour variants originally described by the authors of the species (Reinke \& Berthold, 1879). Because colour variants alone were insufficient to investigate the mechanism underlying genetic variation in this fungus, further genetic markers were sought by using ultraviolet irradiation. This paper deals with the isolation and characterization of these additional selective markers, and describes the pleiotropic effects of some of the auxotrophic mutations obtained.

\section{METHODS}

Four isolates of Verticillium albo-atrum were isolated from wilted hop plants at East Malling Research Station, Kent, two from outbreaks of fluctuating wilt (numbered V 1805, V 1809) and two from progressive outbreaks (V 1790, V 1813). Neither the strain V 1809 nor any culture derived from it formed black torulose hyphae, whereas the others produced them abundantly; none formed the microsclerotia characteristic of Verticillium dahliae Kleb.

A medium pressure Hanovia XII ultraviolet (u.v.) lamp, emitting about $95 \%$ of its radiation at $2537 \AA$, was used to induce mutations which were then selected

* Present address : Department of Botany, Queen's College, Dundee, Scotland. 
for those that blocked the synthesis of essential metabolites. Conidia spread on the surface of a nutritionally complete agar medium (CM; Pontecorvo, Roper, Hemmons, Macdonald \& Bufton, 1953) at 400/plate were exposed at $20 \mathrm{~cm}$. from the u.v. source; under these conditions the radiation intensity was about $104 \mu \mathrm{w} . / \mathrm{cm}^{2}$. From exposures at different time-intervals to determine the irradiation-survival curve, an exposure of 20 sec., giving only $3 \%$ survival, was chosen as a convenient mutagenic dose. The surviving conidia produced viable colonies after 4 days in darkness at $\mathbf{2 3}^{\circ}$. A bulk inoculum of conidia + mycelium was then transferred from each colony that grew from a surviving conidium to $\mathbf{C M}$ in plates in which the inocula were arranged in the regular pattern used in colony replications (Pontecorvo et al. 1953). These cultures were then replicated from CM to Czapek-Dox agar media on which about $0.5 \%$ of the survivors failed to grow. As CM medium contains hydrolysed yeast nucleic acid and several vitamins, the failure of any strain to grow on Czapek-Dox medium was almost certainly because it could not synthesize an essential metabolite supplied by one of these three mixtures. Accordingly, the strains unable to grow on Czapek-Dox medium alone (auxotrophs) were tested for their capacity to grow when it was supplemented with hydrolysed casein, yeast nucleic acid or a vitamin mixture.

Each auxotroph responded to one of these supplements, thus identifying its nutritional requirements either as an amino acid, organic base or vitamin, depending on which supplement allowed the mutant to grow. Slope cultures of the mutants were then established on CM, and the specific requirement determined by auxanography (Pontecorvo, 1949). Auxanographs were made by mixing $1 \mathrm{ml}$. of a spore suspension $\left(5 \times 10^{6} / \mathrm{ml}\right.$.) of the nutritional mutant in $15 \mathrm{ml}$. molten Czapek-Dox agar at $42^{\circ}$ and immediately pouring this into plates. The appropriate supplements were then placed individually in very small amounts around the periphery of the agar. Areas of growth response soon developed.

Mutants resistant to certain growth inhibitors were also sought. A necessary first step was to assess the concentrations inhibitory to several nutritional mutants of independent origin. To do this the nutritional mutants were grown in the replicating pattern on CM. This template was then used to provide inoculum that was replicated on a range of concentrations of the growth inhibitors incorporated in CM. Attempts to select relatively resistant mutants were then made by spreading dense spore suspensions of the sensitive starting strains on CM containing an inhibitory and therefore selective, concentration of each substance.

\section{RESULTS}

\section{Nutritional mutants}

Figure 1 shows the properties of conidia of strain V 1790 that survived different doses of u.v. radiation. Each point plotted is the mean survival on eight agar plates each spread with about 400 conidia. The percentage survival is plotted on scale $\mathbf{A}$, and the curve shows the relationship between percentage survival and exposure time. The straight line drawn to represent the relationship between log. percentage survival and exposure was plotted with reference to scale $B$, and fits the data well. It indicates that the killing of Verticillium conidia follows first-order kinetics.

The proportion of mutants among survivors after treatment with a mutagen 
generally reaches a maximum at mutagenic doses which are over $90 \%$ lethal. Exposures of 20 sec. gave about $3 \%$ survival and the survivors were screened for nutritional mutations by replication and auxanography as already described. Table 1 shows details of the origins of the irradiated conidia and the numbers of u.v. irradiation-induced mutants obtained. The most frequent type of mutant, 13 in all, required vitamins, of which six could not synthesize biotin. All the mutants responding to nucleic acid had a specific requirement for adenine. After some of the strains had been labelled with one nutritional requirement they were re-irradiated

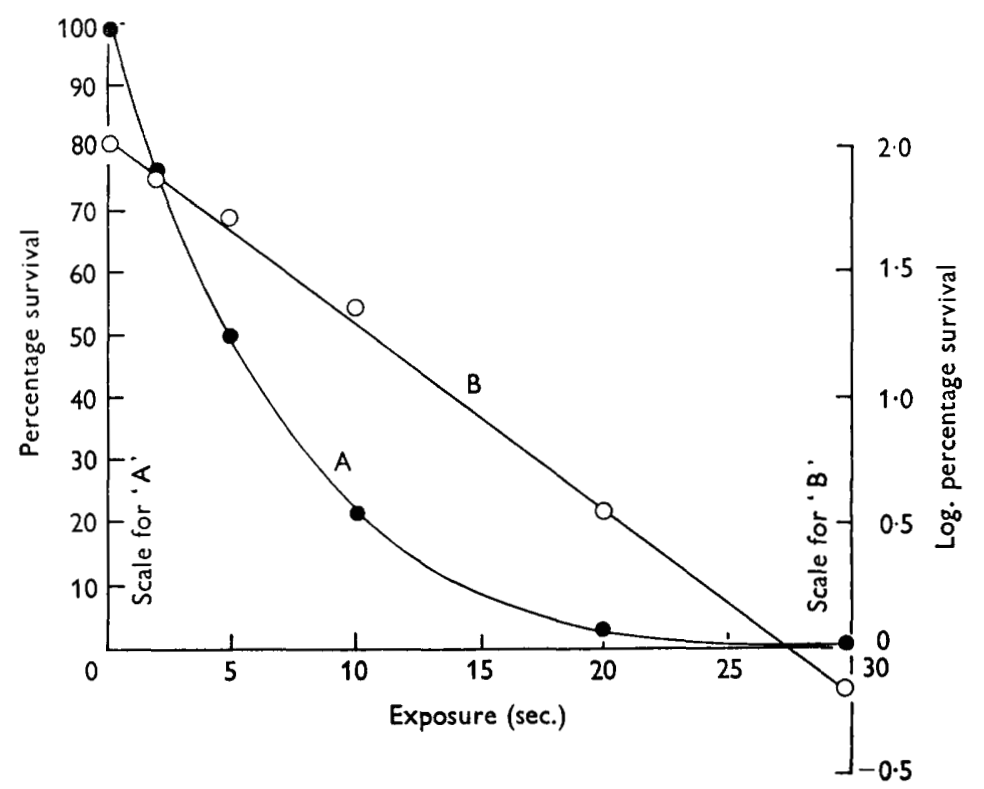

Fig. 1. Survival of conidia of Vericillium albo-atrum (strain V1790) to u.v.-irradiation when exposed on a nutritionally complete medium $(C M)$. A, plotted on linear scale; B, plotted on log. scale.

Table 1. Nutritionally deficient mutants of Verticillium albo-atrum produced by ultraviolet irradiation

$\begin{array}{cccccc}\begin{array}{c}\text { Serial number } \\ \text { of wild-type } \\ \text { culture }\end{array} & \begin{array}{c}\text { Survivors } \\ (3 \% \text { level })\end{array} & \text { Casein } & \begin{array}{c}\text { Nucleic } \\ \text { acid }\end{array} & \text { Vitamins } & \text { Total } \\ \text { V1790 } & 1006 & 1 & 2 & 2 & 5 \\ \text { V1813 } & 1140 & 2 & 1 & 3 & 6 \\ \text { V1809 } & 1528 & 1 & 2 & 5 & 8 \\ \text { V1805 } & 1575 & 3 & 2 & 3 & 8 \\ \text { Total } & 5249 & 7 & 7 & 13 & 27\end{array}$

to add a second marker (second-order mutants); one double auxotroph was exposed a third time, yielding two third-order mutants. Table 2 shows the proportions of mutants among the first, second and third-order survivors.

The relative ease with which the mutations were detected indicates that the conidia were uninucleate and also that the nuclei were haploid, for nutritional 
deficiencies in this fungus are recessive (Hastie, 1962). Too few mutants were detected to justify a statistical treatment of the data, but mutations seemed to be less frequent among survivors of the second and third irradiations. A slight trend in this direction would be expected because there are progressively fewer nutritional requirements detectable, by the methods used, after the later irradiations, as single auxotrophs were exposed at the second irradiation and double auxotrophs at the third.

Table 2. Frequencies of first-, second-and third-order ultraviolet irradiationinduced mutants of Verticillium albo-atrum

$\begin{array}{cccc}\begin{array}{c}\text { Order of } \\ \text { irradiation }\end{array} & \begin{array}{c}\text { Survivors } \\ \text { tested }\end{array} & \text { Mutants } & \begin{array}{c}\text { Proportion of } \\ \text { mutants }\end{array} \\ \text { First } & 1911 & 11 & 1: 174 \\ \text { Second } & 2913 & 14 & 1: 208 \\ \text { Third } & 425 & 2 & 1: 213 \\ \text { Total } & 5249 & 27 & 1: 194\end{array}$

\section{Pleiotropic effect of adenineless mutations}

Seven adenineless mutants were recovered. These formed only sparse conidiophores when grown on $\mathbf{C M}$ and most of their conidia were produced in pionnotes (slimy nodular masses of conidia; see Pl. 1, fig. 1). The production of conidiophores was increased by increasing the adenine concentration in the medium. Plate 1, fig. 2, shows an adenineless mutant growing on three different concentrations of adenine incorporated in Czapek-Dox agar. No pionnotes were formed at the highest concentration ( $20 \mu \mathrm{g}$./adenine $\mathrm{ml}$.), when the mutant produced abundant conidiophores typical of wild-type strains. Among more than 5000 survivors of irradiation examined on CM, only seven produced pionnotes, and each required adenine for growth. It can be therefore reasonably assumed that the production of pionnotes was a pleiotropic effect of mutations blocking adenine synthesis.

Wagner \& Mitchell (1955) suggested the following simplified pathway leading to adenine synthesis in micro-organisms:

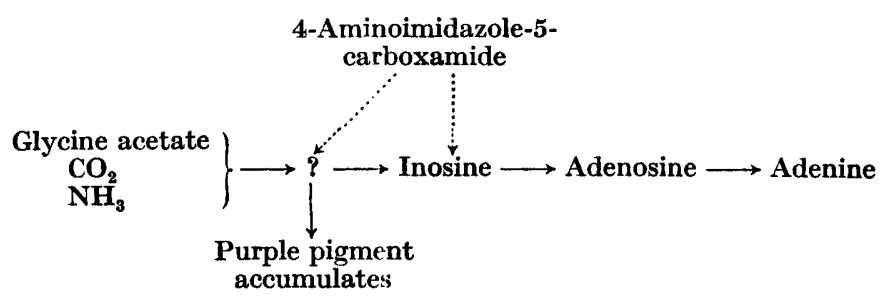

Although a more complex pathway exists, this system was used merely to find the stage at which production of pionnotes might be affected.

The darkly coloured adenineless mutant (Pl. 1, fig. 1) accumulated a purple pigment which diffused into the medium, and at low adenine concentrations it produced fewer pionnotes than did any of the other six adenineless mutants recovered. Table 3 shows the results of an auxanographic test to determine whether the position of the blockage to adenine synthesis was correlated with decreased pionnotal production. The mutant B 11/1, which formed fewer pionnotes and accumulated the purple pigment, was blocked immediately preceding synthesis of adenosine; the 
other mutants were blocked at earlier positions. Experience with other microorganisms suggests that only mutants blocked at the steps preceding 4-aminoimidazole-5-carboxamide fail to produce the purple pigment. This may also be true in Verticillium. Presumably there was no response to 4-aminoimidazole-5-carboxamide because it did not act as an extracellular intermediary, rather than as a result of a blockage at a later stage. Fries, Bergstrom \& Rottenberg (1949) showed that 4aminoimidazole-5-carboxamide was used by certain adenineless mutants of Ophiostoma multiannulatum when a small amount of adenine was provided to initiate growth. This latter condition was met by the auxanographic technique used here by placing a small amount of adenine $\mathrm{HCl}$ at the centre of each auxanograph and the intermediates in adenine synthesis around the edge of the agar medium; none of our adenineless mutants responded to 4-aminoimidazole-5-carboxamide.

Table 3. Responses of seven adenineless mutants of Verticillium albo-atrum in auxanographic test to compare the positions of biochemical blockages to adenine synthesis

$\begin{array}{lcccc}\text { Mutant } & \begin{array}{c}4 \\ \text { Amino-imidazole- } \\ \text { carboxamide }\end{array} & \text { Inosine } & \text { Adenosine } & \text { Adenine } \\ \text { O2 } & - & + & + & + \\ \text { F2 } & - & + & + & + \\ \text { C5/3 } & - & + & + & + \\ \text { C5/4A2 } & - & + & + & + \\ \text { E5 } & - & + & + & + \\ \text { G2 } & - & + & + & + \\ \text { B11/1 } & - & - & + & +\end{array}$

\section{Mutants resistant to groroth inhibitors}

Some basic dyes, respiratory inhibitors, antibiotics and other fungicidal and fungistatic compounds were used in attempts to select resistant mutants by the methods already described. The following four auxotrophic strains were subjected to tolerance tests: V1790, mutant O1, requiring histidine; V1813, mutantE3/1, requiring pyridoxine + nicotinic acid; $\mathrm{V} 1804$, mutant $\mathrm{C} 5 / 4$, requiring methionine + biotin; V 1805, mutant F2, requiring adenine. All four strains (Tables 4 and 5) responded similarly to replication at the concentrations tested. Attempts were made to select mutants resistant to some of the substances at the concentrations listed in the tables. The only spontaneous mutants recovered were resistant to acriflavine, and the attempts to recover spontaneous and u.v. irradiation-induced mutations resistant to some of the other substances failed. The eleven acriflavine-resistant mutants were all obtained from the same culture (V1804 mutantC 5/4) and were therefore probably not independent mutations, but members of a clone produced as a result of a single mutation. For this reason only one mutant was retained; it was purified by isolating a single conidium. After repeated subcultivation on $\mathbf{C M}$ without acriflavine, its survival when exposed to various concentrations of acriflavine was compared with that of the starting strain (V 1804, mutantC5/4). Figure 2 shows the two survival curves. Each point plotted is the mean survival on eight 
plates of $\mathbf{C M}$ containing the different concentrations of acriflavine. The survivors were recorded after incubation for 4 days; later on, the more inhibitory media yielded a few more minute colonies. These continued to grow very slowly and probably arose by enzymatic adaptation. There was never any difficulty in recognizing colonies with a wild-type growth rate.

There is some discrepancy between the tolerance of acriflavine recorded for strain V 1084, mutant C5/4 in Table 4 and that given in Fig. 2. The greater tolerance when tested by replicating was probably caused by the greater concentration of the

Table 4. Tolerance of Verticillium albo-atrum mutants to toxic substances incorporated in complete medium

\begin{tabular}{|c|c|c|c|c|c|c|}
\hline & \multicolumn{3}{|c|}{$\begin{array}{c}\text { Reaction on } \mathbf{C M} \\
\text { containing toxin at } \\
\text { these concns. } \\
(\mu \mathrm{g} . / \mathrm{ml} .)\end{array}$} & \multirow{2}{*}{$\begin{array}{c}\text { Selection } \\
\text { concn.* } \\
(\mu \mathrm{g} . / \mathrm{l} .)\end{array}$} & \multirow{2}{*}{$\begin{array}{l}\text { Spores } \\
\text { tested } \\
\left(\times 10^{8}\right)\end{array}$} & \multirow{2}{*}{$\begin{array}{l}\text { Mutants } \\
\text { detected }\end{array}$} \\
\hline & 1 & 10 & 50 & & & \\
\hline Acriflavine & + & + & - & 100 & 180 & 11 \\
\hline Crystal violet & + & - & - & 10,20 & 92 & $\mathbf{0}$ \\
\hline $\begin{array}{l}\text { 2-4-Dinitrophenol quinoline- } \\
\text { sulphate }\end{array}$ & + & + & + & 50 & 30 & 0 \\
\hline Malachite green & + & \pm & - & 100 & 89 & $\mathbf{0}$ \\
\hline Methyl violet & + & + & - & 20 & 92 & $\mathbf{0}$ \\
\hline Night blue & + & + & \pm & . & . & . \\
\hline Sodium pentachlorophenate & - & - & $=$ & $\mathbf{5}$ & 30 & $\mathbf{0}$ \\
\hline
\end{tabular}

Symbols: + , normal growth rate; \pm , reduced growth rate; - , no growth.

* No attempts were made to select for mutants resistant to materials that allowed growth at $50 \mu \mathrm{g} . / \mathrm{ml}$.

Table 5. Tolerance of Verticillium albo-atrum mutants to a range of antibiotics incorporated in complete medium

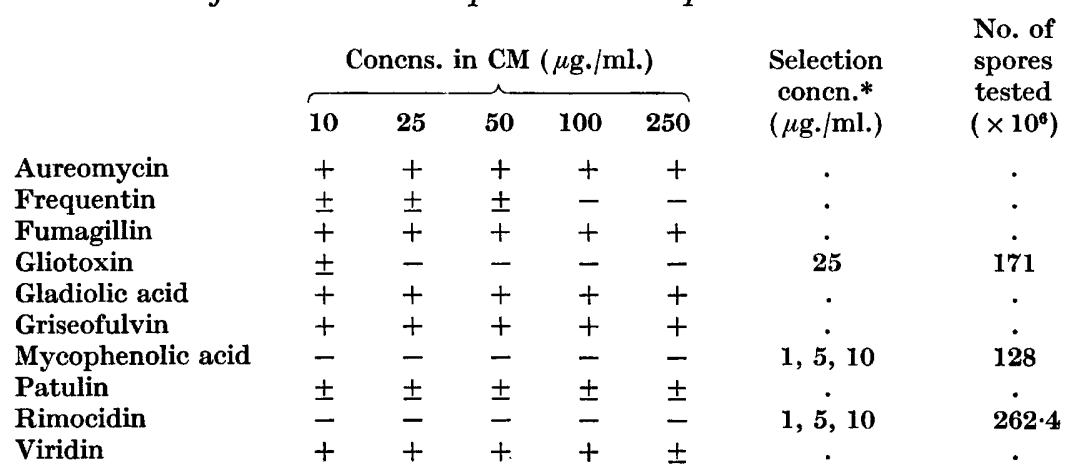

Symbols: + , normal growth rate; \pm , reduced growth rate;,- no growth.

* No attempts were made to select for mutants resistant to materials that allowed growth at $50 \mu \mathrm{g} . / \mathrm{ml}$.

inoculum. Each point inoculated by replicating received many conidia, perhaps several thousands, whereas each site inoculated by spreading a spore suspension would usually receive only one conidium. The survival curve for the resistant mutant (Fig. 2) shows that it succumbed to acriflavine only at concentrations 


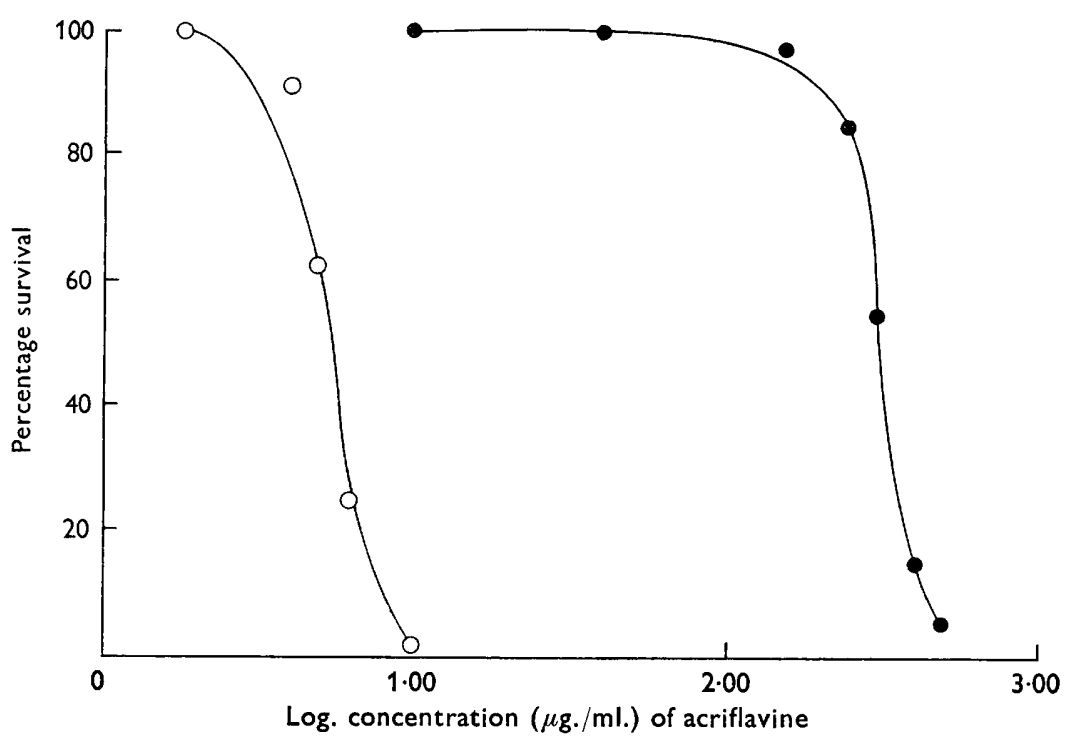

Fig. 2. Survival of un-irradiated conidia of Verticillium albo-atrum on complete agar medium containing acriflavine. $O$, sensitive strain; $O$, resistant mutant.

above $500 \mu \mathrm{g} . / \mathrm{ml}$. This concentration incorporated in CM has been found useful for classifying genetic recombinants as sensitive or resistant in work on the parasexual mechanism of variation in Verticillium (Hastie, 1962).

\section{DISCUSSION}

This work was done to provide the genetic markers necessary to detect and elucidate any system of genetic recombination in Verticillium albo-atrum. The

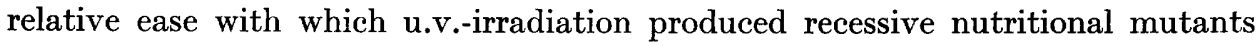
confirmed that the conidia are uninucleate and was an encouraging sign that genetic analysis would be possible. In multinucleate conidia, a recessive mutation in one nucleus would be phenotypically masked by the dominance of the wild-type alleles in other nuclei. The recessive phenotype could then be detected in this or other imperfect fungi only by taking many monoconidial isolates from the colony produced by each irradiated propagule. Such single-conidial isolations proved to be unnecessary in $V$. albo-atrum, thus supporting the evidence that most of the irradiated spores were uninucleate. This evidence agrees with the cytological observations of at least two authors (Waggoner, 1956; Caroselli, 1957).

The kind of survival curve obtained when the conidia were exposed to u.v.irradiation also agrees with the idea that most Verticillium conidia are uninucleate. However, it should also be remembered that different curves (multi-hit) have been observed for fungi with uninucleate spores, and the kinetics of the effect is therefore not a reliable indication of nuclear number. Buxton, Last $\&$ Nour (1957) found that microconidia of Fusarium were inactivated by u.v.-irradiation according to firstorder kinetics, whereas a higher order kinetics governed the inactivation of spores of Aspergillus niger. Genetical studies, however, suggest that at least a very high proportion of Aspergillus conidia are uninucleate (Pontecorvo et al. 1953). 
If the original wild-type isolates were heterogeneous for heritable characters affecting the detection of recessive mutations, the proportion of mutants detected at the later irradiations would have increased greatly. For example, in any original wild-type cultures that may have yielded conidia with both haploid and diploid nuclei, nutritional deficiencies would have been easily detected only in the haploids. Selection of the mutants after the first irradiation would then have provided only haploid strains for the later irradiations, at which there would have been a consequent increase in the proportions of mutants detected.

We thank Dr P. W. Talboys (East Malling Research Station, Kent) for supplying the cultures of Verticillium albo-atrum isolated from wilted hop, and members of the Photography Department, Rothamsted Experimental Station, for taking the photographs. One of us (A.C.H.) also thanks the Agricultural Research Council for the award of a Research Studentship, during the tenure of which this work was done.

\section{REFERENCES}

Buxton, E. W., LAST, F. T. \& Nour, N. A. (1957). Some effects of ultraviolet radiation on the pathogenicity of Botrytis fabae, Uromyces fabae, and Erysiphe graminis. J. gen. Microbiol. 16, 764.

Caroselli, N. E. (1957). Verticillium wilt of maple. Bull. R.I. agric. Exp. Sta. no. 335.

Fries, N., Bergstrom, S. \& Rottenderg, M. (1949). The effect of various imidazole compounds on the growth of purine-deficient mutants of Ophiostoma. Physiol. Plant. $2,210$.

HASTIE, A. C. (1962). Genetic recombination in the Hop-Wilt fungus Verticillium alboatrum. J. gen. Microbiol. 27, 373.

IsaAc, I. (1949). A comparative study of pathogenic isolates of Verticillium. Trans. Brit. mycol. Soc. 32, 137.

Pontecorvo, G. (1949). Auxanographic techniques in biochemical genetics. J. gen. Microbiol. 3, 122.

Pontecorvo, G., Roper, J. A., Hemmons, L. M., Macdonald, K. D. \& Bufton, A. W. J. (1953). The genetics of Aspergillus nidulans. Advanc. Genet. 5, 141.

Reinke, J. \& Berthold, G. (1879). Die Zersetzung der Kartoffel durch Pilze. Untersuchungen aus dem Botanischen Laboratorium der Universität Göttingen, $1,1$.

Robinson, D. B., Larson, R. H. \& Walker, J. C. (1957). Verticillium wilt of potato in relation to epidemiology, symptoms and variability of the pathogen. Res. Bull. Wis. agric. Exp. Sta. no. 202.

vaN DEN ENde, G. (1958). Untersuchungen über den Pflanzenparasiten Verticillium alboatrum. Acta Bot. Neerlandica, 7, 665.

WaGgoner, P. E. (1956). Variation in Verticillium albo-atrum from potato. Plant. Dis. Reptr. 40, 429.

WAGNer, R. P. \& Mitchell, H. K. (1955). Genetics and Metabolism. New York: John Wiley and Sons Inc.

\section{EXPLANATION OF PLATE}

Fig. 1. Adenineless mutants of Verticillium albo-atrum growing on a nutritionally complete medium and showing morphological differences. A, mutant B11/1 accumulating purple pigment in the medium and forming no pionnotes; B, mutant F2, with no purple pigment, but producing pionnotes.

Fig. 2. Adenineless mutant F2 of Verticillium albo-atrum growing on Czapek-Dox agar containing three different concentrations of adenine. A, $20 \mu \mathrm{g} . / \mathrm{ml}$.; B, $2 \cdot 0 \mu \mathrm{g} . / \mathrm{ml}$.; C, $0 \cdot 2 \mu \mathrm{g} . / \mathrm{ml}$. 
Journal of General Microbiology, Vol. 28, No. 4

Plate 1

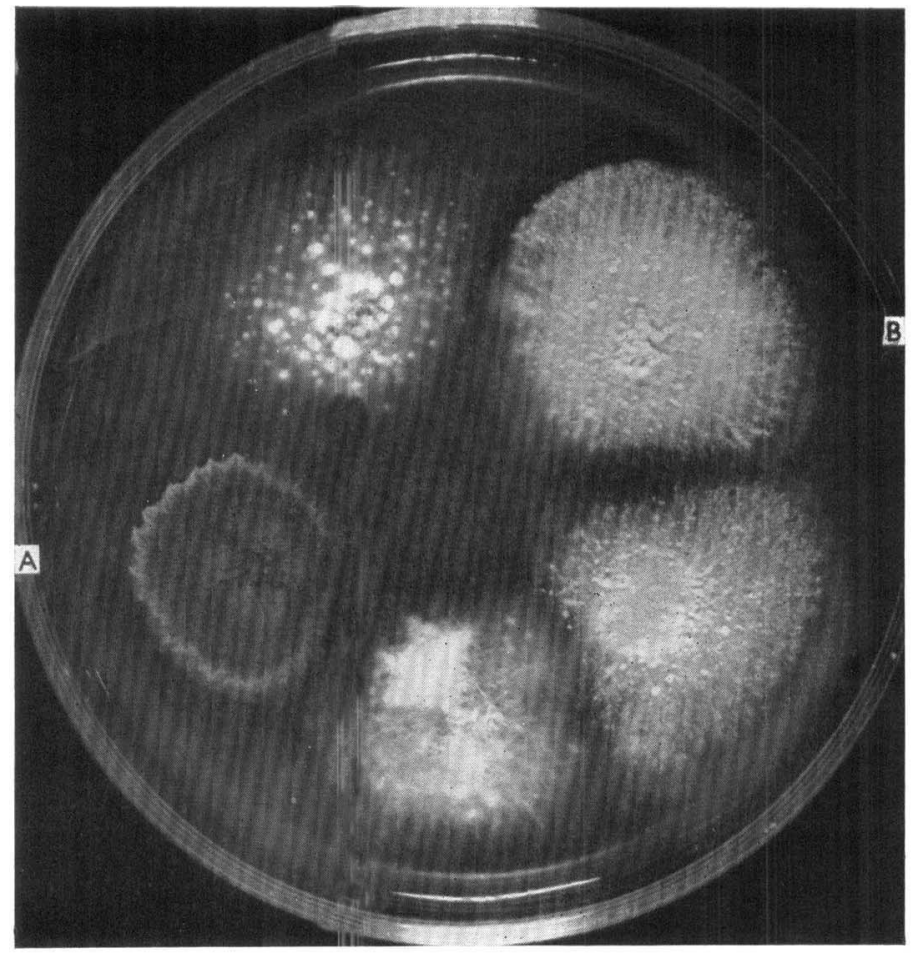

Fig. 1

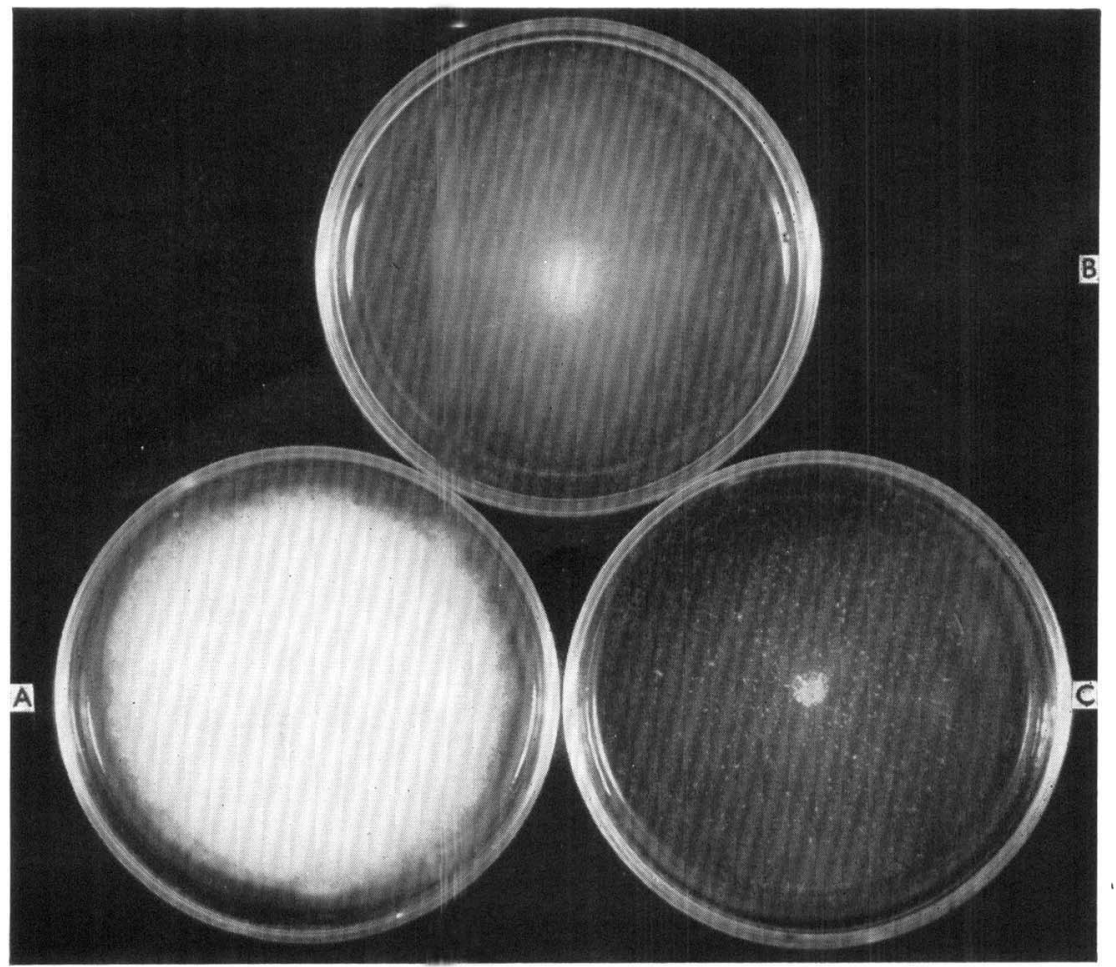

Fig. 2

E. W. BUXTON AND A. C. HASTIE

(Facing $p .632$ ) 
